\title{
Magneto-optical Properties of (Pt/Co)/X/IZO (X = Ta, Au, Pt, Ru and Ag) Structures for Magneto-optical Spatial Light Modulators
}

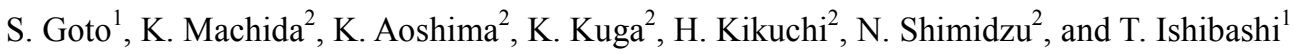 \\ ${ }^{1}$ Department of Materials Science and Technology, Nagaoka University of Technology, 940-2188 Niigata, Japan \\ ${ }^{2}$ Science \& Technology Research Laboratories, Japan Broadcasting Corporation (NHK), 157-8510 Tokyo, Japan
}

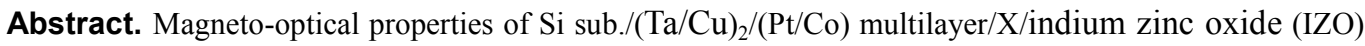
$(\mathrm{X}=\mathrm{Ta}, \mathrm{Au}, \mathrm{Pt}, \mathrm{Ru}$, and $\mathrm{Ag})$ are studied. Kerr rotations, reflectivities and figures of merit of the structures are compared with those of $(\mathrm{Ta} / \mathrm{Cu})_{2} /(\mathrm{Pt} / \mathrm{Co})$ multilayer/X $(\mathrm{X}=\mathrm{Ta}, \mathrm{Au}, \mathrm{Pt}, \mathrm{Ru}$, and $\mathrm{Ag})$ with IZO layers calculated by the virtual optical constant method. Two peaks caused by interference are confirmed in both of those spectra, and the Kerr rotation of the samples with $\mathrm{Ta}$, $\mathrm{Au}$, and Pt capping layer reached 1.2 degrees at approximately $2.7 \mathrm{eV}$. The sample with Au capping layer gave the highest figure of merit.
\end{abstract}

\section{Introduction}

Spatial light modulators (SLM) having high spatial resolutions and high driving speeds are required to achieve holographic three-dimensional displays. We are developing a magneto-optical spatial light modulator (MO-SLM) driven by spin transfer switching using giant magneto-resistive (GMR) device [1], which is capable of meeting the requirements. For practical applications, an improvement of the light modulation by increasing of the magneto-optical (MO) Kerr rotation is required. In addition, high reflectivity is necessary for the reflection type MO-SLM. In order to enhance the MO effect of the MO-SLM, influences of the structures of GMR devices on their MO and optical properties should be investigated. Suzuki et al. found that Kerr rotations of epitaxial Fe film grown on thick Au layers were enhanced with photon energies around the plasma frequencies of $\mathrm{Au}$ [2]. We found that GMR films with Ag spacers showed that Kerr rotations were larger than that with $\mathrm{Cu}$ spacers [3], we also found that Kerr rotations of $\mathrm{Pt} / \mathrm{Co}$ GMR changes with materials used for $3 \mathrm{~nm}$-thick capping layers [4]. In this paper, we report on Kerr rotations and reflectivities of tri-layers, $\mathrm{Pt} / \mathrm{Co}$ multilayer/capping layer/top transparent electrodes.

\section{Experiments}

Films of $(\mathrm{Ta}(3 \mathrm{~nm}) / \mathrm{Cu}(50 \mathrm{~nm}))_{2} / \mathrm{Co}(0.1 \mathrm{~nm}) / \mathrm{Pt}(1.1$ $\mathrm{nm}) /(\mathrm{Co} \quad(0.26 \mathrm{~nm}) / \mathrm{Pt} \quad(1.1 \mathrm{~nm}))_{4}$ were deposited on thermally oxidized silicon substrates by DC magnetron sputtering technique. Ta, $\mathrm{Au}, \mathrm{Pt}, \mathrm{Ru}$, and $\mathrm{Ag}(3 \mathrm{~nm})$ for a capping layer, and indium zinc oxide (IZO) $(350 \mathrm{~nm})$ for top transparent electrode layers were deposited on the films by ion beam sputtering technique.

The reflectivity spectra were measured at normal incidence by a spectrometer (Shimadzu: SolidSpec-3700) for a wavelength between $400-700 \mathrm{~nm}$. The MO polar Kerr rotation spectra were measured by a MO spectrometer using the polarization modulation technique for a visible region with a wavelength between $400-700$ $\mathrm{nm}$. The angle of incidence of the light from the surface normal was 15 degrees for Kerr measurements.

The Kerr rotation and reflectivity spectra were calculated with the virtual optical constant method [5] Models used for the calculations are $\mathrm{Cu} / \mathrm{Ta}(3 \mathrm{~nm}) / \mathrm{Cu}(50$ $\mathrm{nm}) /(\mathrm{Pt} / \mathrm{Co})$ multilayer $(6.64 \mathrm{~nm}) / \mathrm{X}(3 \mathrm{~nm})$ with and without IZO $(350 \mathrm{~nm})$, where $\mathrm{X}$ is a capping layer of Ta, $\mathrm{Au}, \mathrm{Pt}, \mathrm{Ru}$, and $\mathrm{Ag}$. The refractive index, extinction coefficient, Kerr rotation and Kerr ellipticity of $\operatorname{Pt}(1.70$ $\mathrm{nm}) / \mathrm{Co}(0.44 \mathrm{~nm})$ multilayer reported in Ref. [6] having similar composition to the $\mathrm{Pt} / \mathrm{Co}$ in the samples were used for the calculation models. This is because we do not have the optical and MO properties of $\mathrm{Pt} / \mathrm{Co}$ multilayer used in this study.

\section{Results and discussion}

Figure 1 shows reflectivity spectra of metals for the capping layers. The reflectivities of $\mathrm{Au}$ and $\mathrm{Ag}$ are higher than $80 \%$ for photon energies below approximately 2.3 and $3.4 \mathrm{eV}$, respectively. These reflectivities decrease at each plasma frequency. $\mathrm{Ta}, \mathrm{Pt}$, and $\mathrm{Ru}$ show relatively flat spectra because their plasma frequencies appear at higher than $5 \mathrm{eV}$. 
Figure 2 shows reflectivity spectra calculated for $(\mathrm{Cu} / \mathrm{Ta})_{2} /(\mathrm{Pt} / \mathrm{Co})$ multilayer/capping layer. A model with Ag capping layer give the highest reflectivity. The reflectivity for the model with Au capping layer is the second highest for lower photon energies. However, it decreases above $2.2 \mathrm{eV}$. This result seems to correspond to the decline in the reflectivity of bulk Au as observed in Fig. 1.

The Kerr rotation spectra calculated for $\mathrm{Cu} / \mathrm{Ta} / \mathrm{Cu}$ $/(\mathrm{Pt} / \mathrm{Co})$ multilayer/capping layer are shown in Fig. 3. The model with Au capping layer has the largest Kerr rotation at photon energies above $2 \mathrm{eV}$ and the model of Ta capping layer has the largest Kerr rotation below $2 \mathrm{eV}$. For $\mathrm{Ag}$ capping layer, the Kerr rotation spectrum is similar to that for Au capping layer. The Kerr rotations are relatively small for $\mathrm{Ru}$ and Pt capping layers.

Figure 4 shows measured reflectivity spectra of $\mathrm{Si}$ sub./(Ta/Cu $)_{2} /(\mathrm{Pt} / \mathrm{Co})$ multilayer/X/IZO (X = Ta, Au, Pt, $\mathrm{Ru}$, and $\mathrm{Ag}$ ). It is found that the reflectivities oscillate due to an interference effect. The samples with $\mathrm{Au}$ and $\mathrm{Ag}$ capping layers give relatively high reflectivities, corresponding to high reflectivities of $\mathrm{Au}$ and $\mathrm{Ag}$ as mentioned above. The calculated reflectivity spectra are shown in Fig. 5. Those shapes and the orders of magnitude of the reflectivities are well reproduced, corresponding to the experimental results shown in Fig. 4.

Figure 6 shows Kerr rotation spectra measured for the

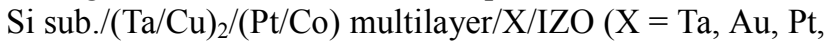
$\mathrm{Ru}$, and $\mathrm{Ag}$ ). Similarly to the reflectivity spectra, the Kerr rotations increase periodically. The maxima of the Kerr rotations are found at approximately 2 and $2.7 \mathrm{eV}$ where the reflectivities become minima. The Kerr rotation reaches $0.7-0.9$ degrees at $2 \mathrm{eV}$ and $1.2-1.5$ degrees at $2.7 \mathrm{eV}$ for the samples with Ta, Au and Pt capping layer, while samples with $\mathrm{Ru}$ and $\mathrm{Ag}$ capping layer have relatively small Kerr rotation.

Figure 7 shows the Kerr rotation spectra calculated for the models with the different capping layers and IZO layers. The models with $\mathrm{Ta}$ and $\mathrm{Au}$ show relatively large Kerr rotations, which is similar to the experimental results. Since the calculated Kerr rotations of the models with $\mathrm{Au}$ and Ag capping layers and without IZO are relatively higher above $2.1 \mathrm{eV}$ as shown in Fig. 3, we expected that those of the models with IZO would give the same result.

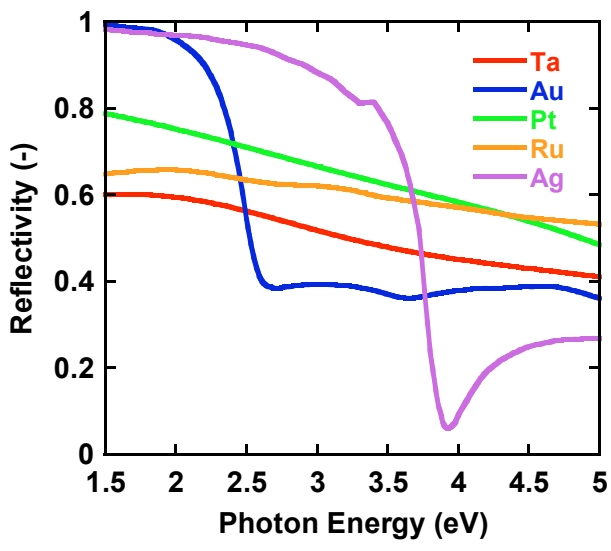

Fig. 1. Calculated reflectivity spectra of metals used as the capping layers.

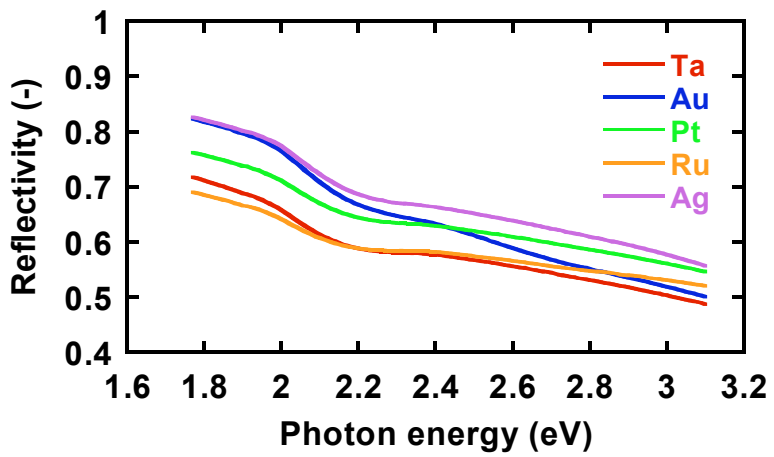

Fig. 2. Reflectivity spectra calculated for $(\mathrm{Cu} / \mathrm{Ta}) /(\mathrm{Pt} / \mathrm{Co}) / \mathrm{X}(\mathrm{X}$ $=\mathrm{Ta}, \mathrm{Au}, \mathrm{Pt}, \mathrm{Ru}$, and $\mathrm{Ag}$ ).

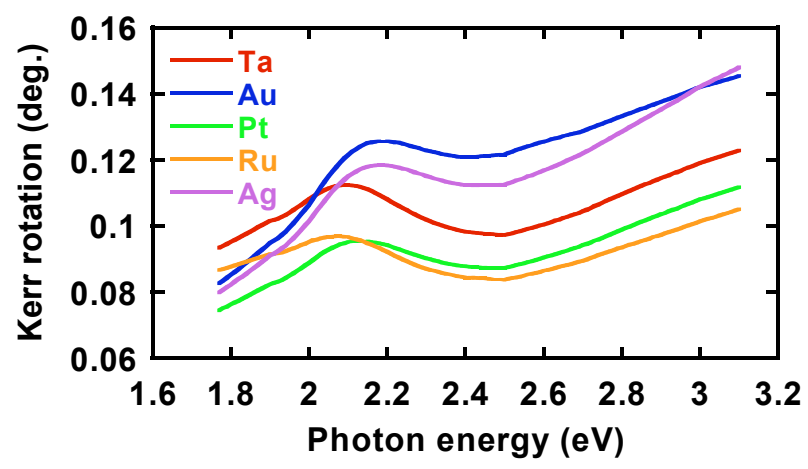

Fig. 3. Calculated Kerr rotation spectra of $(\mathrm{Cu} / \mathrm{Ta}) /(\mathrm{Pt} / \mathrm{Co}) / \mathrm{X}(\mathrm{X}$ $=\mathrm{Ta}, \mathrm{Au}, \mathrm{Pt}, \mathrm{Ru}$, and $\mathrm{Ag}$ ).

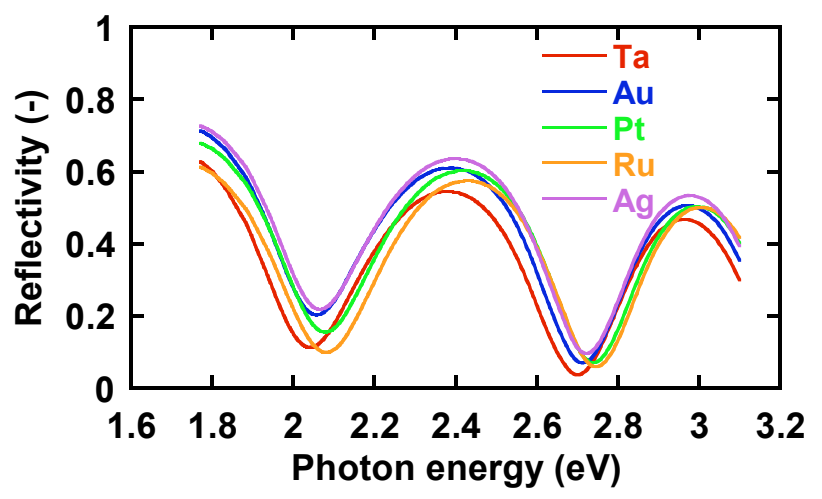

Fig. 4. Measured reflectivity spectra of $\mathrm{Si}$ sub./(Cu/Ta)/(Pt/Co) $/ \mathrm{X} / \mathrm{IZO}(\mathrm{X}=\mathrm{Ta}, \mathrm{Au}, \mathrm{Pt}, \mathrm{Ru}$, and $\mathrm{Ag})$.

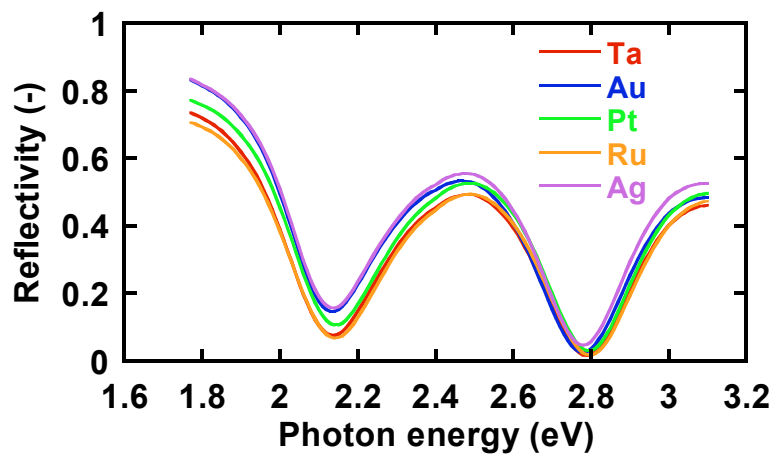

Fig. 5. Calculated reflectivity spectra of $(\mathrm{Cu} / \mathrm{Ta}) /(\mathrm{Pt} / \mathrm{Co}) / \mathrm{X} / \mathrm{IZO}$ $(\mathrm{X}=\mathrm{Ta}, \mathrm{Au}, \mathrm{Pt}, \mathrm{Ru}$, and $\mathrm{Ag})$. 


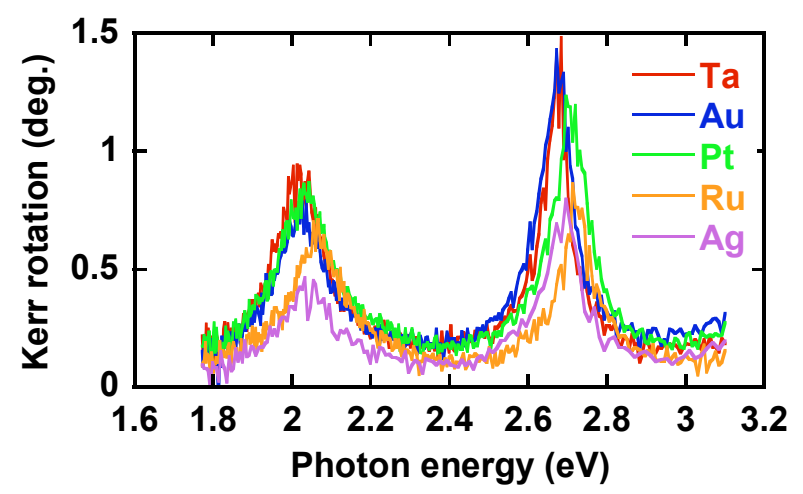

Fig. 6. Measured Kerr rotation spectra of $\mathrm{Si}$ sub./(Cu/Ta) $/(\mathrm{Pt} / \mathrm{Co}) / \mathrm{X} / \mathrm{IZO}(\mathrm{X}=\mathrm{Ta}, \mathrm{Au}, \mathrm{Pt}, \mathrm{Ru}$, and $\mathrm{Ag})$.

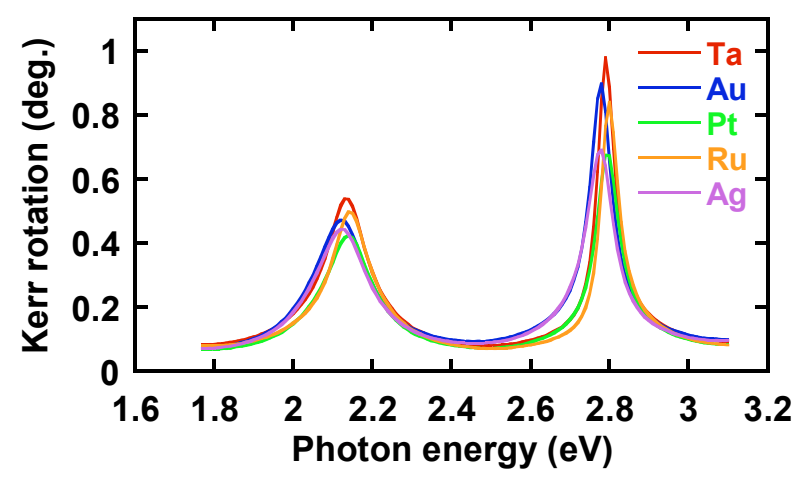

Fig. 7. Calculated Kerr rotation spectra of $(\mathrm{Cu} / \mathrm{Ta}) /(\mathrm{Pt} / \mathrm{Co}) / \mathrm{X}$ $/ \mathrm{IZO}(\mathrm{X}=\mathrm{Ta}, \mathrm{Au}, \mathrm{Pt}, \mathrm{Ru}$, and $\mathrm{Ag})$.

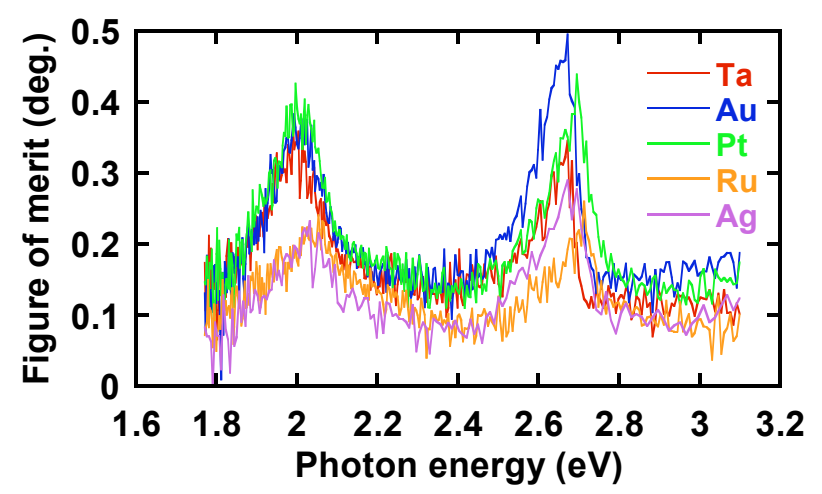

Fig. 8. Measured figure of merit spectra of $\mathrm{Si} \operatorname{sub} . /(\mathrm{Cu} / \mathrm{Ta})$ $/(\mathrm{Pt} / \mathrm{Co}) / \mathrm{X} / \mathrm{IZO}(\mathrm{X}=\mathrm{Ta}, \mathrm{Au}, \mathrm{Pt}, \mathrm{Ru}$, and $\mathrm{Ag})$.

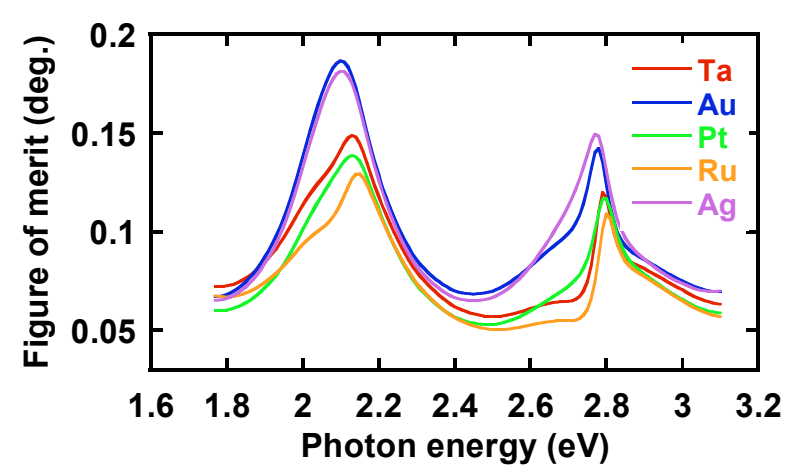

Fig. 9. Calsulated figure of merit spectra of $(\mathrm{Cu} / \mathrm{Ta}) /(\mathrm{Pt} / \mathrm{Co}) / \mathrm{X}$ /IZO (X = Ta, Au, Pt, Ru, and Ag).
However, the calculated Kerr rotation of the peak at 2.8 $\mathrm{eV}$ for the models with $\mathrm{Ta}$ and $\mathrm{Ru}$ are higher than those with $\mathrm{Au}$ and $\mathrm{Ag}$ contrary to the expectation. These results indicate that the predictions about the magnitudes of the Kerr rotations are difficult by only the data of individual layers composed the samples.

Those Kerr rotations seem to be mainly influenced by the MO properties of $\mathrm{Pt} / \mathrm{Co}$ multilayers. Sato et al. showed that measured MO spectra of $\mathrm{Pt} / \mathrm{Co}$ multilayer are different with the calculated spectra using models contains only unalloyed Pt and Co layers, and explain the inconsistent as due to formations of PtCo alloy layers at the interfaces between Pt and Co layers [7], and Moog et al. [8] conclude that the magnetization induced in the $\mathrm{Pt}$ by the Co causes the difference. To check the influence, we also calculated for $\mathrm{PtCo}$ alloy instead of $\mathrm{Pt} / \mathrm{Co}$ multilayer. However, we found that tendency of Kerr rotations and reflectivities depending on the capping layers are almost same.

Figure 8 shows the measured figure of merit spectra of Si sub./(Ta/Cu) $/(\mathrm{Pt} / \mathrm{Co})$ multilayer/X/IZO (X = Ta, Au, $\mathrm{Pt}, \mathrm{Ru}$, and $\mathrm{Ag})$, and Figure 9 shows the calculated one. We defined the figure of merit as the product of the Kerr rotation and the square root of the reflectivity. The sample with $\mathrm{Au}$ capping layer shows the highest figure of merit in the experiment and the simulation. We found that the capping layers with small extinction coefficients have a tendency to give high figures of merit in the simulation.

\section{Summary}

Enhancements of Kerr rotations and reflectivities of Pt/Co multilayers caused by top transparent electrode layers and capping layers were investigated. The maxima of the Kerr rotation spectra of the samples with the $\mathrm{Ta}, \mathrm{Au}$, and $\mathrm{Pt}$ capping layers were larger than 1.2 degrees. The samples with the $\mathrm{Au}$ and $\mathrm{Ag}$ capping layers showed high reflectivities, and the Au capping layer gave the highest figure of merit experimentally.

\section{Acknowledgements}

This research was supported by the National Institute of Information and Communications Technology (NICT).

\section{References}

1. K.Aoshima, N. Funabashi, K. Machida, Y. Miyamoto, K. Kuga, T. Ishibashi, N. Shimidzu, F. Sato, J. Display Technol. 6, 374 (2010)

2. Y. Suzuki, T. Katayama, S. Yoshida, K. Tanaka, K. Sato, Phys. Rev. Lett. 68, 3355 (1992)

3. K. Aoshima, Y. Ohtsuka, Y. Hashimoto, N. Funabashi, K. Machida, K. Kuga, H. Kikuchi, N. Shimidzu, J. Appl. Phys 109, 07C917 (2011)

4. T. Ishibashi, M. Naganuma, S. Tang, S. Goto, K. Machida, K. Furukawa, K. Aoshima, N. Funabashi, K. Kuga, H. Kikuchi, N. Shimidzu, J. Magn. Soc. Jpn. 36, 70 (2012) 
5. K. Ohta, A. Takahashi, T. Deguchi, T. Hyuga, S. Kobayashi, H. Yamaoka, SPIE 382, 252 (1983)

6. K. Sato, H. Hongu, K. Tsuzukiyama, J. Watanabe, Y. Togami, J. Magn. Soc. Jpn. 15 (Suppl. S1), 29 (1991)
7. K. Sato, H. Hongu, H. Ikekame, J. Watanabe, K. Tsuzukiyama, Y. Togami, M. Fujisawa, T. Fukazawa, Jpn. J. Appl. Phys. 31, 3603 (1992)

8. E. R. Moog, J. Zak, S. D. Bader, J. Appl. Phys. 69, 880 (1991) 